\title{
The Research on the Traditional Filial Piety Education of the Youth
}

\author{
Yang Pan \\ Ideological and political Teaching, XiJing University, shaanxi ,710123,china.
}

Keywords: Adolescents; Filial piety; Deletion; Education.

\begin{abstract}
The paper takes youth as the research object. It analyzes the problems existing in current teenage filial piety, points out the need to strengthen teenage filial piety education, which must pass through the joint efforts of society, school, family and youth itself, carries forward the Chinese traditional culture of filial piety, strengthens teenage filial piety education and promotes the ideological and moral construction.
\end{abstract}

\section{Introduction}

The filial piety culture is an important part of the Chinese traditional culture, however, this kind of traditional virtues in the youth actually appears the flow of the different degree. Since our country entered 1999, the elder people's pension problem is also the concern of the society, and it also arouses people's thinking about the filial piety education of the youth. Lack of Filial Piety Concept of the youth is highly concemed due to families. The school, the society and the youth themselves, the reconstruction of filial piety are facing a severe challenge. Therefore, in the process of constructing a harmonious society, to streng then the youth's traditional filial piety education is particularly important.

\section{The necessity of carrying forward the traditional filial piety}

An ove rvie w of the traditional filial piety. The filial piety is one of the most important traditional virtues in our country. To some extent, the Chinese traditional culture can be called the culture of filial piety. The traditional Chinese society is based on the filial piety, the development of filial piety. Chinese traditional filial piety culture is a composite concept and is rich in content, involving a wide range. From the respect of analysis, it mainly includes the following contents, namely: Pro king, nourish and Shi disease, conduct, hospice, which is today we must advocate and implement the filial piety culture concept.

The necessity of strengthening the youth $s$ traditional filial piety education in the process of building a harmonious society. Is the heritage of the Chinese traditional culture.

Filial piety culture is an important part of Chinese traditional culture, which is the oldest and most basic, the most important and the most profound traditional ethical values in Chinese culture. To strengthen traditional filial piety education, to deepen the understanding of the traditional filial piety culture and to pursue filial piety are what the Chinese nation's traditional culture heritages and carries forward.

Image long is the basic moral requirements, is conducive to the cultivation of their consciousness

In September 2001, the Central Committee of the Communist Party of China promulgated the citizen moral Implementation Outline ", putting forward the basic moral norms, the unplayable as every citizen's basic morality. To strengthen young people's traditional filial piety education can make them know that showing filial respect to parents is every citizen's basic moral requirements. Children's res ponsibilities are conducive to the cultivation of teenagers' sen se of respect and support.

\section{Problems existing in the current youth filial piety}

The lack of the consciousness of filial piety in the youth. Disreg ard the upbringing of the parents, no Thanksgiving Awareness 
For individuals, there is nothing more kind than the valuable life given by parents. Parents are the ones which should be given more thanks to. Filial piety is the traditional virtue of Chinese culture. However, in the youth group, filial piety has been very rare. Due to the improvement of living conditions, teenagers are often spoiled and do not have enough communicate with parents. There are few teenagers who understand the hardships what their parents went through, so they often dis regard of parents' kindness and show self centered and are lack of responsibilities.

Due to changes in the economic development and the family structure, the one-child families in rural areas also increased, the only child becomes the "little emperor" or "little princess" of a family. from "overweening" consciousness. They are often self - centered to meet their own desires, and rarely take the initiative care of others. They are lack of responsibilities for their parents, the home and the whole community.

The absence of filial piety in the youth. Disrespect, parents elders.

Filial piety is the traditional virtue of Chinese, but the phenomenon of the present shows that the filial consciousness of the teenagers is lacking. In the attitude of the parents, children often show impatience and disrespect, and cannot see the kindness of their parents so they show bad attitude towards their parents, not treating their parents and elders well.with parenting, parents often.

In the countryside, the only child becomes more and more and has become the center of the family. Combined with some ideas and unhealthy ways and customs of presents, some bad habits are kept in adolescent children. With rebellious mood, parents refuse to accept the discipline. When there are disagreement between children and their parents, children often spar and even fight with their parents.

Do not know how to repay their parents, compassionate, parent-child relation ship is indifference.

Living conditions are getting better. The child's home will meet and develop their dependence on psychology. Children only know parents' requests, but donot understand the parents who bear the pressure of life and do not know the hardship of parents. They cannot understand their parents' kindness when their self needs are not met, which will hurt their parents, which causes extremely bad relationship between parents and children.

The dislocation of ideological concept and practical action. The lack of filial piety in the youth has become more and more serious, and it becomes a thought-provoking social problem. Young parents are one of the major characteristics of the words: filial behavior. In the "respect" problem, the general performance shows more word but less actions. Parents of children care very thoughtful and subtle, but rarely speak out. But the filial piety to parents of the youth only stays in oral, rarely in action. Teenagers now grow to accept compulsory education, in school to learn knowledge of traditional filial piety and also to recognize the filial piety of the necessity, but they fail to implement action, ideas and practical action to appear serious dislocation.

\section{The reasons for the lack of filial piety and the lack of behavior of the teenagers}

Objective aspects. The deviation of the values of the values of the interests under the environment of the market economy.

After the establishment of the socialist market economy, the national standard of living has improved. People are in the pursuit of the maximization of economic benefits at the same time, "money first" and "greed" and other ideas gradually fill the minds of people. Its influence has continually expands, resulting in most of the deviation values.

The change of family structure, the status of elder men and the dislocation of the family filial piety education

The elder people in our country are the family structure of the feudal family, and elder people occupy the absolute authority in families. Now, the family structure has changed greatly, and elder people are gradually at the edge of family power.

The education of filial piety in school is not in place, and there is imbalance in moral education proportion in the education evaluation system 
Under the pressure of the examination oriented education in our country, schools only pay more attention on higher grade and more achievements for students after they entered schools. The importance of students' ideological and moral education is not fully focused on. Schools ignore the cultivation of students' personality and humanity. School education of filial piety means single, education is vague in content, textbooks involve the contents of filial piety that very few, which is a lack of specific practice guid ance. School filial education relies on the theory to instill. Students cannot experience in theThanks giving feelings in practice.

Subjective aspects. The neglect of the importance of traditional culture, the inheritance of the traditional filial piety

Adolescents living condition is getting better and better, they are pursuing fashion and advocating modern life style and idea, while the traditional Chinese culture, old-fashioned, outdated things with no new ideas are lack due en thusiasm for them. The school do not take the traditional filial piety as a compulsory course, parents do not play a good role model, the young people ignore the importance of the traditional culture or the inheritance of the traditional filial piety.

The filial piety education in family and school is not in place. With the increasing of the one-child family, children gradually develop the habit of egoistic, self-centered. They refuse to accept the discipline, and the family and school filial piety education is not in place without the good models.

The thought is not mature which is affected by the outside bad influence. Teenagers are in the special period of the prog ress of life, physiological and psychological development. Their thoughts are often immature and unstable, and their views of the world, life, values has not formed. At this point, they contact and understand the outside world from many channels, showing great curiosity for the outside world. But there is a lack of distinguishing ability, the independen ce of the self consciousness is not strong, and their self-control ability is weak. They are easy to relax to own request, disoriented. Due to the immaturity of teenagers' ideological and the impact of adverse external thought, children are merely to satisfy their desires, while ignoring the parents for their kindness.

\section{How to strengthen the filial piety education in teenagers}

Objective aspects. Under the condition of socialist market economy, establish the correct value orientation

In the era of rapid economic development, people pay more attention on the monetary interests, money is the concept of generalization, filial piety concept is gradually diluted in this context. Under the condition of the socialist market economy, people must accord to the characteristics of the times and cultural needs, of traditional filial piety of reasonable combing, dig out the essential part of them, and realize the modern conversion of the traditional filial piety.

Parents should set examples to strengthen filial piety education for their children. As the saying goes, parents are the first teacher of child. Parents have significant impact on the behaviors of their children. The behavior of the parents cannot only affect the direction of the development of child ren, but also decide whether the children can win the trust and respect from family education. Parents should establish the correct filial piety, in the ideological and moral and life details of the exacting requirements of their own, to instill filial piety children. Their own practice filial piety, for their children, do a good demonstration.

Schools should pay more attention to moral education to strengthen filial piety education and to carry out practical activities

The school is the most concentrated place for young people, but also the focal position of the education activities. Schools should pay more attention to moral education, strengthen the traditional filial piety schooling, and make preparations for the relevant preparatory work, to ensure that the majority of young people in the school to accept the traditional filial piety education system.

Subjective aspects. To strengthen the recognition and development of the traditional filial piety culture 
The Chinese national culture has a long history, and it is the spiritual wealth of our country's working people for thousands of years. In the Confucian culture and the East Asian cultural circle, filial piety is an important way to deal with the parent child relationship.Teenagers should be from a young age to cultivate interest and enthusiasm of our traditional culture, to deepen the understanding of traditional filial piety, to recognize the importance of respecting and providing for the elderly, and to enhance their sense of mission and honor their parents, which has an important role to the personality formation and development of the young people..

The family and the school of filial piety education should be done in practice. The youth is in the critical period of receiving education. The most important is family education and school education. Teenagers should be placed under the influence of teachers and parents, words and deeds, understanding the connotation of Chinese traditional filial piety and regulating their own behaviors. To understand the parents' selfless love, germination grateful feelings, cultivate and raise awareness of parents and pay the feelings of the action to honor their parents. In the education of schools, teachers and parents, words and deeds, should constantly improve their cognition of traditional filial piety and learn the knowledge internalization, and implement the action of parents.

Increase the quality and establish the correct value orientation. Young people must keep on learning to enrich themselves, in addition to learn the basic knowledge of science and culture, but also to understand the excellent traditional culture of China and filial piety, to know how to show thanks, in order to improve their scientific and cultural qualities, the ideological and moral quality.

\section{Conclusions}

Strengthen the young generation of traditional filial piety schooling, training them to establish a correct concept of filial piety, to their parents and elders of filial piety. The lack of the concept of filial piety in the countryside is not only caused by the teenagers themselves, but also caused bythe society, schools, families and so on. People only improve the understanding of traditional filial piety, the consciousness to honor their parents of the children is the obligation and responsibility which should be paid atention to. A culture of respecting forms the whole society, in order to ease the elderly pension problems. Only bu continuous learning, can adolescents improve their ideological and moral qualities, cultivate and raise awareness, build harmonious family culture and promote the construction of rural spiritual civilization.

\section{References}

[1] Jiayin Yan. Gratitude education to the contemporary youth research -- in the traditional filial piety perspective [J]. Southwest University Journal (SOCIAL SCIENCE EDITION), 2008,7.

[2] Xiang Li, the historical changes of Chinese traditional filial piety culture and its value [J]. unknown, in 201019 Volume 5 period.

[3] Yunfang Guo. The Chinese Youth Development Forum, which is [J]. China Youth Development Forum, 2006.

[4] Li Zeng. The absence and reconstruction of filial piety culture in contemporary youth [J]. Third China Youth Development Forum, 2007.

[5] Hongping Xue. Promoting the harmonious development of traditional filial piety to promote the harmonious development of young people [J]. Third China Youth Development Forum, 2007.

[6] Li Zhang. The modern positioning of Chinese traditional filial piety from the perspective of human science [J]. Journal of Shaanxi Normal University, 2006.

[7] Qunzhong Xiao. The cultural effect of filial piety for the aged [J]. theoretical vision, the 1 period of 2009. 
[8] Yiran Li. Beijing: Chinese filial [M]. radio and television press, 2010 April.

[9] Lan Zhu. Development history of Chinese traditional filial piety thought [M]. Beijing: National School of Administration press, March 2011.

[10] Pumin Cai, Rui Guo. The cause and Countermeasure of the lack of Rural Filial Piety Concept and Countermeasures [J]. Journal of Shanxi Agricultural University, 2009 (8). 